Bischoff-Ferrari, H.A., Willett, W.C., Orav, E.J., Lips, P., Meunier, P.J., Lyons, R.A., Flicker, L., Wark, J., Jackson, R.D., Cauley, J.A., Meyer, H.E., Pfeifer, M., Sanders, K.M., Stähelin, H.B., Theiler, R. \& Dawson-Hughes, B. (2012). A Pooled Analysis of Vitamin D Dose Requirements for Fracture Prevention. New England Journal of Medicine, 367, 4049.

Copyright: @ 2012 Massachusetts Medical Society

This is the published version of an article accepted for publication in the New England Journal of Medicine following peer review. The published version is available at the journal home page of the publisher, Massachusetts Medical Society. This version was made available in the UWA Research Repository 1 August 2013 in compliance with the publisher's policies on archiving in institutional repositories.

Use of the article is subject to copyright law in respect of the copyright owner. Any use other than personal use requires the permission of the copyright owner. 


\title{
A Pooled Analysis of Vitamin D Dose Requirements for Fracture Prevention
}

\author{
Heike A. Bischoff-Ferrari, M.D., Dr.P.H., Walter C. Willett, M.D., Dr.P.H., \\ Endel J. Orav, Ph.D., Paul Lips, M.D., Pierre J. Meunier, M.D., \\ Ronan A. Lyons, M.D., M.P.H., Leon Flicker, M.D., John Wark, M.D., Ph.D., \\ Rebecca D. Jackson, M.D., Jane A. Cauley, Dr.P.H., \\ Haakon E. Meyer, M.D., Ph.D., Michael Pfeifer, M.D., Kerrie M. Sanders, Ph.D., \\ Hannes B. Stähelin, M.D., Robert Theiler, M.D., and Bess Dawson-Hughes, M.D.
}

From the Center on Aging and Mobility, University of Zurich and Waid City Hospital, Zurich, and the Department of Rheumatology, University Hospital Zurich, Zurich (H.A.B.-F.), the Department of Rheumatology, City Hospital Triemli, Zurich (R.T.), and the Department of Geriatrics, University Hospital Basel, Basel (H.B.S.) - all in Switzerland; the Departments of Nutrition (W.C.W.) and Biostatistics (E.J.O.), Harvard School of Public Health, and the Bone Metabolism Laboratory, Jean Mayer USDA Human Nutrition Research Center on Aging at Tufts University (B.D.-H.) - both in Boston; the Department of Internal Medicine and Endocrinology and the EMGO Institute for Health and Care Research, VU University Medical Center, Amsterdam (P.L.); Claude Bernard University of Lyon, Lyon, France (P.J.M.); the Department of Public Health, Swansea University, Swansea, United Kingdom (R.A.L.); the Western Australian Centre for Health and Ageing, University of Western Australia, Crawley (L.F.), and the Department of Medicine, Bone and Mineral Service, Royal Melbourne Hospital (J.W.), and the Department of Clinical and Biomedical Sciences, Barwon Health (K.M.S.), University of Melbourne, Melbourne, VIC - all in Australia; the Departments of Internal Medicine, Endocrinology, Diabetes, and Metabolism, Ohio State University, Columbus (R.D.J.); the Department of Epidemiology, University of Pittsburgh, Pittsburgh (J.A.C.); the University of Oslo and Norwegian Institute of Public Health, Oslo (H.E.M.); and the Institute of Clinical Osteology and German Osteology Foundation, Bad Pyrmont, Germany (M.P.). Address reprint requests to Dr. Bischoff-Ferrari at the Center on Aging and Mobility, University Hospital, Zurich, Gloriastr. 25, 8091 Zurich, Switzerland.

This article was updated on July 5, 2012, at NEJM.org.

N Engl J Med 2012;367:40-9.

DOI: 10.1056/NEJMoal109617

Copyright (C) 2012 Massachusetts Medical Society.

\section{ABSTRACT}

\section{BACKGROUND}

The results of meta-analyses examining the relationship between vitamin D supplementation and fracture reduction have been inconsistent.

\section{METHODS}

We pooled participant-level data from 11 double-blind, randomized, controlled trials of oral vitamin D supplementation (daily, weekly, or every 4 months), with or without calcium, as compared with placebo or calcium alone in persons 65 years of age or older. Primary end points were the incidence of hip and any nonvertebral fractures according to Cox regression analyses, with adjustment for age group, sex, type of dwelling, and study. Our primary aim was to compare data from quartiles of actual intake of vitamin D (including each individual participant's adherence to the treatment and supplement use outside the study protocol) in the treatment groups of all trials with data from the control groups.

\section{RESULTS}

We included 31,022 persons (mean age, 76 years; 91\% women) with 1111 incident hip fractures and 3770 nonvertebral fractures. Participants who were randomly assigned to receive vitamin $\mathrm{D}$, as compared with those assigned to control groups, had a nonsignificant 10\% reduction in the risk of hip fracture (hazard ratio, $0.90 ; 95 \%$ confidence interval [CI], 0.80 to 1.01 ) and a $7 \%$ reduction in the risk of nonvertebral fracture (hazard ratio, 0.93; 95\% CI, 0.87 to 0.99). By quartiles of actual intake, reduction in the risk of fracture was shown only at the highest intake level (median, 800 IU daily; range, 792 to 2000), with a $30 \%$ reduction in the risk of hip fracture (hazard ratio, 0.70 ; $95 \% \mathrm{CI}, 0.58$ to 0.86 ) and a $14 \%$ reduction in the risk of any nonvertebral fracture (hazard ratio, $0.86 ; 95 \% \mathrm{CI}, 0.76$ to 0.96). Benefits at the highest level of vitamin D intake were fairly consistent across subgroups defined by age group, type of dwelling, baseline 25-hydroxyvitamin D level, and additional calcium intake.

\section{CONCLUSIONS}

High-dose vitamin D supplementation ( $\geq 800$ IU daily) was somewhat favorable in the prevention of hip fracture and any nonvertebral fracture in persons 65 years of age or older. (Funded by the Swiss National Foundations and others.) 
PPROXIMATELY 75\% OF FRACTURES OCcur in people 65 years of age or older. ${ }^{1}$ By 2050, the worldwide incidence of hip fractures is expected to increase by $240 \%$ among women and $310 \%$ among men. ${ }^{2}$

One strategy to prevent fractures in this population might be universal vitamin D supplementation. However, the results of several study level meta-analyses and one pooled participantlevel analysis do not agree. Although one triallevel meta-analysis of double-blind, randomized, controlled trials suggested an $18 \%$ reduction in the incidence of hip fracture and a $20 \%$ reduction in the incidence of any nonvertebral fracture at a received dose of no less than 482 IU of vitamin D per day, ${ }^{3}$ three study-level meta-analyses ${ }^{4-6}$ and one pooled analysis of participant-level data ${ }^{7}$ from open-design and blinded trials suggested that vitamin D may have no effect on total fractures $^{4}$ or may reduce hip fracture by 7 to $16 \%$, if combined with calcium supplementation, regardless of the dose of vitamin D. ${ }^{4-7}$ The discordant findings may be explained, in part, by differences in the criteria for including trials in the analyses, with respect to blinding, vitamin D formulation (oral vs. injectable), or accommodations for nonadherence. Our analysis was designed to estimate the effects of vitamin D supplementation according to the actual intake of each participant, rather than simply the dose to which the participant was randomly assigned.

\section{METHODS}

\section{POOLED STUDIES}

We attempted to identify all double-blind, randomized, controlled trials involving persons 65 years of age or older that evaluated oral vitamin D supplementation, alone or in combination with calcium, as compared with a control (placebo or calcium alone); that included data on low-trauma fractures; and that were published on or before August 31, 2011. We conducted searches of Medline, the Cochrane Central Register of Controlled Trials, and Embase. Of 14 qualifying trials, 2 were unavailable (lost files), both of which showed a significant reduction in fracture risk at a treatment dose that was equivalent to 800 IU of vitamin D per day. ${ }^{8,9}$

We included 12 studies (with a total of 33,277 participants) and received the source data for 30,011 participants 65 years of age or older from
11 trials, including type and date of fracture and dates of study entry and exit. For the 1 study of the 12 (with 3266 participants) for which events were identified by month, ${ }^{10}$ we made the assumption that events had occurred in mid-month. One study (with 2255 participants) provided the dose once yearly ${ }^{11}$; in the other 11 studies (with 31,022 participants), the dose of vitamin D was given daily, ${ }^{10,12-19}$ weekly, ${ }^{20}$ or every 4 months. ${ }^{21}$ The RECORD (Randomised Evaluation of Calcium or Vitamin D) trial, which had a factorial design, was split into study A (vitamin D vs. placebo) and study B (vitamin D plus calcium vs. calcium alone) trials. ${ }^{16}$ The work was done collegially with no limitations on confidentiality, except the removal of patient identifiers. All the included studies required that participants provide written informed consent.

\section{VARIABLES}

Because adherence to the study treatment was documented differently in the published trials, we incorporated data on adherence according to a predefined protocol. For 7 trials, data on adherence were available at the participant level. For the 4 trials without participant-level reports of adherence, we applied the mean value for adherence $\left(80 \%{ }^{14,19,21}\right.$ or $\left.95 \% 15\right)$ of that trial to the individual participant doses. Vitamin D supplementation outside the study protocol was permitted in 5 of 11 trials, ${ }^{14-17,21} 3$ of which provided participant-level data that we incorporated in the assessment of actual intake in the primary analysis. ${ }^{15-17}$ The other 2 trials either allowed up to $200 \mathrm{IU}^{14}$ of vitamin D per day or included persons if they had a vitamin D intake of less than 400 IU per day, ${ }^{21}$ without providing participantlevel information on additional intake. Data on sex and type of dwelling were available for all participants from all 12 studies. For 1 of the 12 studies, ${ }^{10}$ we did not have participant-level data on age, so we applied the cohort average to each participant. Fracture events in all trials were verified by a review of medical records. We excluded vertebral fractures because they were not documented systematically in any of the trials.

\section{PRIMARY ANALYSES}

The primary end points were the risks of hip fracture and any nonvertebral fracture. The primary analyses compared the actual intake of vitamin D supplementation, in quartiles, between 
treated participants and controls (with actual intake calculated as the assigned treatment dose plus any additional supplemental dose, with adjustment for adherence). In a sensitivity analysis, we excluded any additional supplemental dose outside the study protocol from the calculation of actual intake.

To establish a bridge to earlier meta-analyses and explain the additional information gained by the comparison of actual-intake amounts, we included two additional analyses: an intention-totreat analysis that compared participants who had been randomly assigned to receive vitamin $\mathrm{D}$ or a control, and an analysis according to treatment dose that maintained the assigned randomization status (vitamin D vs. control) and the assigned treatment dose ( $\leq 400$ IU per day vs. $>400$ IU per day). All analyses were controlled for study, sex, age group, and type of dwelling.

\section{INTERNAL VALIDATION ANALYSIS}

We performed an internal validation study to compare the highest quartile of actual intake of vitamin D with the lowest quartile, regardless of the randomized study-group assignment, including controls. Furthermore, with available baseline measurements of 25-hydroxyvitamin D from a subset of 4383 participants, we performed a threshold assessment of the association between the baseline quartile of 25-hydroxyvitamin D level and the prospective risk of hip fracture or any nonvertebral fracture, independently of study group, age group, sex, type of dwelling, and study.

\section{SENSITIVITY ANALYSES}

In sensitivity analyses, we included 1 additional trial, by Sanders et al., ${ }^{11}$ because it used a different treatment regimen, consisting of an annual high dose $(500,000 \mathrm{IU})$ of vitamin $\mathrm{D}$, and we added 100 IU of vitamin D to the actual-intake amount for participants in the 2 trials in which a small dose of additional vitamin $\mathrm{D}$ was allowed but not documented. ${ }^{14,21}$ To extend our participant-level data to the 2 randomized, controlled trials (by Chapuy et al. ${ }^{9}$ and Trivedi et al. ${ }^{8}$ ) for which the source data were not available, we performed a trial-level meta-analysis that combined our pooled findings from the 11 randomized, controlled trials with the trial-level findings of these 2 trials in a random-effects meta-analysis.

\section{SUBGROUP ANALYSES}

In predefined subgroup analyses we assessed the effect of actual intake of vitamin D according to age group (younger than 75 years, 75 to 84 years, or 85 years or older), type of dwelling (community dwelling vs. institution), baseline level of 25hydroxyvitamin $\mathrm{D}$ ( $<30 \mathrm{nmol}$ per liter vs. $\geq 30 \mathrm{nmol}$ per liter), and additional dose of a calcium supplement in the treatment group $(<1000 \mathrm{mg}$ per day vs. $\geq 1000 \mathrm{mg}$ per day).

\section{STATISTICAL ANALYSIS}

After establishing homogeneity among the 11 individual trials for both fracture end points overall and at the actual-intake quartile level, we pooled the individual participant-level data and used Cox proportional-hazards regression analysis to assess the incidence of hip fracture or any nonvertebral fracture. For the primary analyses, we performed only one analysis for hip fracture and one analysis for nonvertebral fracture in which we compared all quartiles of actual intake to the control group, and it was our a priori expectation that the effect would be greatest at the highest dose. In the nonprimary analyses, because of the potential for false positive results due to multiple testing, we used a P value of 0.0125 to indicate significance. Since four subgroups were considered for each of two types of fracture outcome, an interaction term for the highest actual intake level of vitamin D and each subgroup was added to the model, and a Bonferroni-adjusted $P$ value of less than 0.00625 was required for significance.

All analyses were adjusted for study, age group, sex, and type of dwelling; however, the analyses were not adjusted for calcium supplementation, owing to colinearity between doses of vitamin $\mathrm{D}$ and calcium supplementation. All reported P values are two-sided, and the proportional-hazards assumptions were satisfied for the primary analyses for both hip fracture and any nonvertebral fracture. Additional frailty anal$y e^{22}$ were carried out to ensure that the results were robust with respect to the allowance specified for correlation within the study. The results of these analyses are not reported, since they remained consistent and significant. Analyses were conducted with SAS software, version 9.2 (SAS Institute). 


\begin{tabular}{|c|c|c|c|c|c|}
\hline \multirow[t]{2}{*}{ Variable } & \multirow[t]{2}{*}{$\begin{array}{c}\text { Control Group } \\
(\mathrm{N}=15,495)\end{array}$} & \multicolumn{4}{|c|}{$\begin{array}{l}\text { Treatment-Group Quartile } \\
\qquad(\mathrm{N}=15,527)\end{array}$} \\
\hline & & $\begin{array}{c}0-360 \text { IU/day } \\
(N=3935)\end{array}$ & $\begin{array}{c}361-637 \text { IU/day } \\
(N=3836)\end{array}$ & $\begin{array}{c}638-791 \text { IU/day } \\
(\mathrm{N}=3790)\end{array}$ & $\begin{array}{c}792-2000 \mathrm{IU} / \text { day } \\
(\mathrm{N}=3966)\end{array}$ \\
\hline Median dose - IU/day & & 340 & 547 & 693 & 800 \\
\hline \multicolumn{6}{|l|}{ Age } \\
\hline Mean - yr & $76.4 \pm 7.5$ & $75.2 \pm 6.4$ & $72.5 \pm 6.1$ & $78.0 \pm 8.8$ & $79.8 \pm 6.2$ \\
\hline $65-74 \mathrm{yr}-\%$ & 48.5 & 53.0 & 72.0 & 43.9 & 25.7 \\
\hline $75-84 \mathrm{yr}-\%$ & 38.7 & 38.0 & 22.2 & 29.0 & 65.6 \\
\hline$\geq 85 \mathrm{yr}-\%$ & 12.8 & 9.0 & 5.8 & 27.1 & 8.7 \\
\hline Female sex — no. (\%) & $14,082(90.9)$ & $3510(89.2)$ & $3696(96.4)$ & $3216(84.9)$ & $3670(92.5)$ \\
\hline Living in institution — no. (\%) & $4,760(30.7)$ & $573(14.6)$ & $380(9.9)$ & $1970(52.0)$ & $1863(47.0)$ \\
\hline \multicolumn{6}{|l|}{ Supplement } \\
\hline Vitamin D, actual intake - IU/day & $100 \pm 160$ & $290 \pm 98$ & $496 \pm 81$ & $692 \pm 41$ & $846 \pm 180$ \\
\hline Calcium, actual intake $-\mathrm{mg} /$ day & $84 \pm 258$ & $396 \pm 393$ & $697 \pm 282$ & $403 \pm 436$ & $830 \pm 460$ \\
\hline \multicolumn{6}{|l|}{ 25-Hydroxyvitamin D level } \\
\hline No. of participants & 2220 & 440 & 679 & 632 & 412 \\
\hline Mean value $-\mathrm{nmol} /$ liter & $47 \pm 24$ & $41 \pm 24$ & $48 \pm 21$ & $54 \pm 29$ & $43 \pm 20$ \\
\hline Pooled studies — no. & 11 & 5 & 5 & 8 & 5 \\
\hline
\end{tabular}

* Plus-minus values are means \pm SD. In the treatment group, there were significant differences in age group, sex, and percentage of participants living in institutions across the quartiles of actual intake of vitamin $D$. The range of actual intake of vitamin $D$ in the highest quartile was unchanged when the one trial with a treatment dose of $2000 \mathrm{IU}$ per day ${ }^{13}$ was excluded.

\section{RESULTS}

\section{CHARACTERISTICS OF THE PARTICIPANTS}

The clinical characteristics of 31,022 participants from 11 trials are shown in Table 1 . Of 4383 participants with baseline measurements of 25-hydroxyvitamin D, $24 \%$ had levels of less than $30 \mathrm{nmol}$ per liter, $62 \%$ had levels of less than $50 \mathrm{nmol}$ per liter, and $88 \%$ had levels of less than $75 \mathrm{nmol}$ per liter. Appendix 1 in the Supplementary Appendix, available with the full text of this article at NEJM.org, shows the assigned treatment doses and actual-intake amounts in each trial.

\section{PRIMARY ANALYSES}

The intention-to-treat analysis showed a nonsignificant $10 \%$ reduction in the risk of hip fracture (hazard ratio, 0.90; 95\% confidence interval [CI], 0.80 to 1.01), which did not differ according to assigned treatment dose. On the basis of our primary comparison of actual intake, however, there was a significant $30 \%$ reduction in the incidence of hip fracture at the highest actual-intake level (792 to 2000 IU per day) in treated participants, as compared with controls (Table 2), with a similar finding for the adherence-adjusted dose, which did not include supplements outside the study protocol (29\% reduction). Notably, there was no reduction in the risk of hip fracture at any actualintake level lower than 792 IU per day.

In the internal validation analysis, regardless of study assignment, the reduction in the risk of hip fracture was 30\% and was significant at the highest actual-intake level (792 to 2000 IU per day), as compared with the lowest actual-intake level (0 to 360 IU per day), suggesting a dose-response relationship. Such a relationship was also suggested by the threshold assessment of hip-fracture risk according to quartile of baseline 25-hydroxyvitamin D level in the 4383 participants for whom serum measurements were available (Fig. 1A).

The intention-to-treat analysis showed a $7 \%$ overall reduction in the risk of nonvertebral frac- 


\begin{tabular}{|c|c|c|c|c|c|c|c|}
\hline \multirow[t]{2}{*}{ Analysis } & \multirow[t]{2}{*}{$\begin{array}{c}\text { No. of } \\
\text { Participants }\end{array}$} & \multicolumn{3}{|c|}{ Hip Fracture } & \multicolumn{3}{|c|}{ Any Nonvertebral Fracture } \\
\hline & & $\begin{array}{c}\text { No. of } \\
\text { Fractures }\end{array}$ & $\begin{array}{c}\text { Relative Risk } \\
(95 \% \mathrm{CI})\end{array}$ & P Value & $\begin{array}{l}\text { No. of } \\
\text { Fractures }\end{array}$ & $\begin{array}{c}\text { Relative Risk } \\
(95 \% \mathrm{CI})\end{array}$ & P Value \\
\hline \multicolumn{8}{|c|}{ Intention-to-treat analysis } \\
\hline Control & 15,495 & 586 & 1.00 & & 1948 & 1.00 & \\
\hline Treatment & 15,527 & 525 & $0.90(0.80-1.01)$ & 0.07 & 1822 & $0.93(0.87-0.99)$ & 0.03 \\
\hline \multicolumn{8}{|c|}{ Treatment-dose analysis } \\
\hline Control & 15,495 & 586 & 1.00 & & 1948 & 1.00 & \\
\hline$\leq 400 \mathrm{IU} /$ day & 10,111 & 255 & $0.89(0.74-1.07)$ & 0.20 & 1225 & $0.96(0.89-1.05)$ & 0.40 \\
\hline >400 IU/day'̄ & 5,416 & 270 & $0.91(0.78-1.06)$ & 0.22 & 597 & $0.89(0.80-0.98)$ & 0.02 \\
\hline \multicolumn{8}{|l|}{ Actual-intake analysis } \\
\hline Control & 15,495 & 586 & 1.00 & & 1948 & 1.00 & \\
\hline 0-360 IU/day & 3,935 & 100 & $1.00(0.79-1.26)$ & 0.99 & 425 & $0.96(0.86-1.07)$ & 0.44 \\
\hline 361-637 IU/day & 3,836 & 110 & $1.03(0.83-1.29)$ & 0.78 & 520 & $1.01(0.91-1.12)$ & 0.85 \\
\hline 638-791 IU/day & 3,790 & 164 & $1.01(0.83-1.23)$ & 0.92 & 419 & $0.90(0.80-1.01)$ & 0.08 \\
\hline 792-2000 IU/day & 3,966 & 151 & $0.70(0.58-0.86)$ & $<0.001$ & 458 & $0.86(0.76-0.96)$ & 0.007 \\
\hline \multicolumn{8}{|l|}{ Sensitivity analysis } \\
\hline Control & 15,495 & 586 & 1.00 & & 1948 & 1.00 & \\
\hline 0-337 IU/day & 3,353 & 84 & $1.01(0.79-1.30)$ & 0.91 & 465 & $1.06(0.95-1.17)$ & 0.32 \\
\hline 338-360 IU/day & 5,652 & 114 & $0.83(0.66-1.05)$ & 0.11 & 619 & $0.89(0.80-0.98) \mathbb{\int}$ & 0.02 \\
\hline 361-699 IU/day & 2,640 & 180 & $1.14(0.93-1.41)$ & 0.21 & 326 & $1.05(0.91-1.22)$ & 0.52 \\
\hline $700-2000 \mathrm{IU} /$ day & 3,882 & 147 & $0.71(0.58-0.87)$ & 0.001 & 412 & $0.81(0.72-0.91)$ & $<0.001$ \\
\hline \multicolumn{8}{|l|}{ Internal validation } \\
\hline 0-360 IU/day & 18,153 & 639 & 1.00 & & 2193 & 1.00 & \\
\hline 361-637 IU/day & 4,976 & 150 & $1.03(0.84-1.26)$ & 0.80 & 681 & $1.04(0.95-1.15)$ & 0.37 \\
\hline 638-791 IU/day & 3,865 & 168 & $1.02(0.84-1.24)$ & 0.83 & 431 & $0.92(0.82-1.03)$ & 0.16 \\
\hline 792-2000 IU/day & 4,028 & 154 & $0.70(0.58-0.86)$ & $<0.001$ & 465 & $0.86(0.77-0.97)$ & 0.01 \\
\hline
\end{tabular}

* All analyses were adjusted for study, age group, sex, and type of dwelling. To limit false positive results and correct for multiplicity, we used a $P$ value of 0.0125 to indicate significance.

$\uparrow$ All trials included doses between 700 and $2000 \mathrm{IU}$ per day.

$\mp$ Among 21,241 participants from the eight trials that used vitamin D combined with any dose of calcium supplementation, a benefit was present only at the highest actual-intake level of vitamin D.

$\int$ In the sensitivity analysis for adherence-adjusted dose without supplements outside the study protocol, 511 participants in the Women's Health Initiative trial ${ }^{17}$ shifted from the highest actual-intake level (792 to $2000 \mathrm{IU}$ per day) and 1356 shifted from the second-highest actualintake level (638 to $791 \mathrm{IU}$ per day) to the second-lowest adherence-adjusted intake level (338 to 360 IU per day). See the Supplementary Appendix for additional information.

ture (hazard ratio, $0.93 ; 95 \% \mathrm{CI}, 0.87$ to 0.99 ), with no risk reduction at doses of $400 \mathrm{IU}$ per day or less (hazard ratio, 0.96 ; $95 \%$ CI, 0.89 to 1.05 ), and an $11 \%$ reduction at doses higher than 400 IU per day (hazard ratio, 0.89 ; $95 \%$ CI, 0.80 to 0.98 ). In the primary comparison of actual intake, the pattern was largely the same as that observed for hip fracture (Table 2). For prevention of nonvertebral fracture, a dose-response relationship was supported by the internal validation analysis (Ta- ble 2) and by the threshold assessment of baseline 25-hydroxyvitamin D level (Fig. 1B). Primary findings at the highest actual-intake level were robust when individual trials were excluded (Appendixes $2 \mathrm{~A}$ and $2 \mathrm{~B}$ in the Supplementary Appendix).

\section{SENSITIVITY ANALYSES}

When we included the trial-level findings for the two trials with missing source data ${ }^{8,9}$ (treatment doses, 800 IU and 833 IU per day) at the highest 
actual-intake level, results were unchanged for hip fracture (relative risk, $0.70 ; 95 \%$ CI, 0.59 to 0.84 ) and any nonvertebral fracture (relative risk, 0.84; $95 \%$ CI, 0.74 to 0.95 ). The inclusion of the trial by Sanders et al., ${ }^{11}$ in which a high annual dose of vitamin $\mathrm{D}$ was administered, attenuated the findings in the intention-to-treat analysis (Appendix 3 in the Supplementary Appendix) and at the highest actual-intake level (Appendixes 2A and 2B in the Supplementary Appendix). The results of additional sensitivity analyses were robust (data not shown), and there was homogeneity among trials at the quartile level of actual intake of vitamin D (Fig. 2A and 2B).

\section{SUBGROUP ANALYSES}

There were no significant interactions, after Bonferroni adjustment, between the highest actual intake of vitamin $\mathrm{D}$ and subgroups defined by age, type of dwelling, baseline level of 25-hydroxyvitamin $\mathrm{D}$, and additional calcium intake (Table 3). This suggests that the effect of the highest actual intake of vitamin D was relatively consistent across these subgroups. However, reduced power, especially in the subset of participants for whom baseline levels of 25-hydroxyvitamin D were available and the subset with additional calcium intake, may have masked some true differences. There was a suggestion that the highest actual-intake level of vitamin $\mathrm{D}$ was less beneficial for the prevention of nonvertebral fracture in participants living in community dwellings than in those living in institutions $(\mathrm{P}=0.02)$, with the $\mathrm{P}$ value indicating a significant difference on the basis of the conventional threshold for significance but not the Bonferroni-adjusted threshold.

\section{DISCUSSION}

This pooled analysis included a large participantlevel data sample of double-blind, randomized, controlled trials of vitamin D supplementation that involved persons 65 years of age or older. The findings suggest that only a high intake of vitamin $\mathrm{D}$ leads to a significant reduction in the risk of fracture - with a $30 \%$ reduction in the risk of hip fracture and a $14 \%$ reduction in the risk of any nonvertebral fracture; this reduction is independent of the assigned treatment dose of vitamin $\mathrm{D}$, age group, sex, type of dwelling, and study. Thus, it is possible that the results of typical intentionto-treat analyses of vitamin D supplementation, as replicated in this pooled analysis with a non-

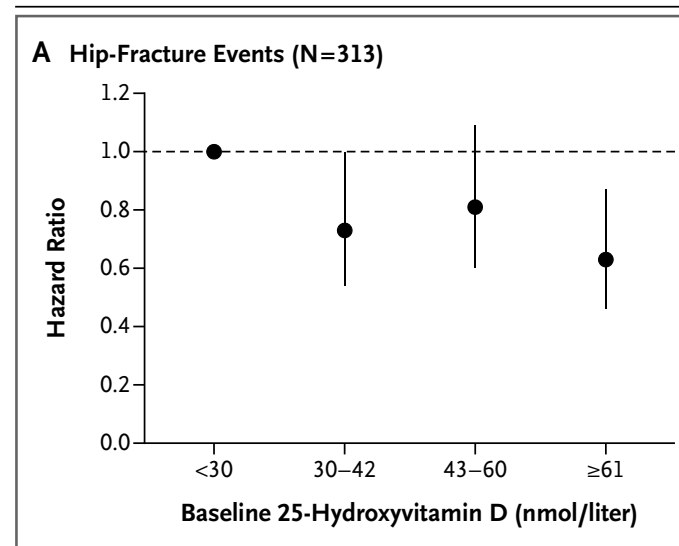

B Nonvertebral-Fracture Events $(\mathrm{N}=914)$

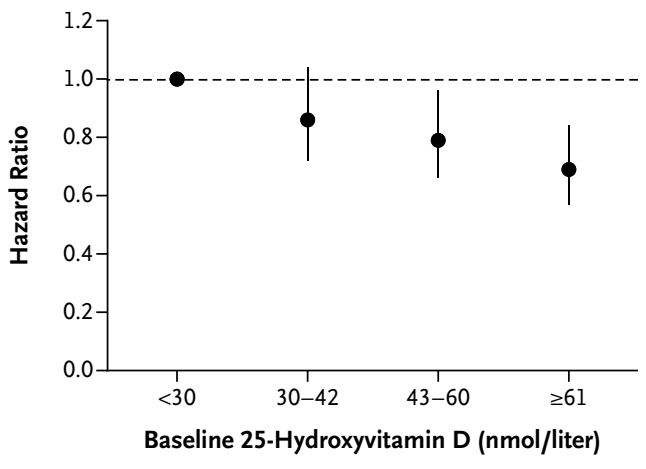

Figure 1. Threshold Assessment for the Risk of Fracture, According to Quartile of Baseline 25-Hydroxyvitamin D Level.

Panel A shows the risk of hip fracture, and Panel B the risk of any nonvertebral fracture. Among the 4383 study participants for whom data on baseline 25 -hydroxyvitamin D levels were available, there were 313 hip and 914 nonvertebral fractures during follow-up. After adjustment for study, group assignment (treatment or control), age group, sex, and type of dwelling, persons 65 years of age or older with baseline serum 25 -hydroxyvitamin $D$ levels of at least $61 \mathrm{nmol}$ per liter, as compared with persons with baseline levels of less than $30 \mathrm{nmol}$ per liter, had a risk of hip fracture that was reduced by $37 \%$ (hazard ratio, $0.63 ; 95 \% \mathrm{Cl}, 0.46$ to 0.87 ) and a risk of any nonvertebral fracture that was reduced by $31 \%$ (hazard ratio, $0.69 ; 95 \% \mathrm{Cl}, 0.57$ to 0.84 ). With higher quartiles of baseline 25-hydroxyvitamin D levels, there was a significant trend toward lower risks of hip fracture $(P=0.02)$ and any nonvertebral fracture $(P<0.001)$. The bars indicate $95 \%$ confidence intervals.

significant $10 \%$ reduction in the risk of hip fracture and a $7 \%$ reduction in the risk of any nonvertebral fracture, underestimate the benefit of vitamin D supplementation. Notably, the benefit at the highest actual-intake level of vitamin D was confirmed in the internal validation analysis, 


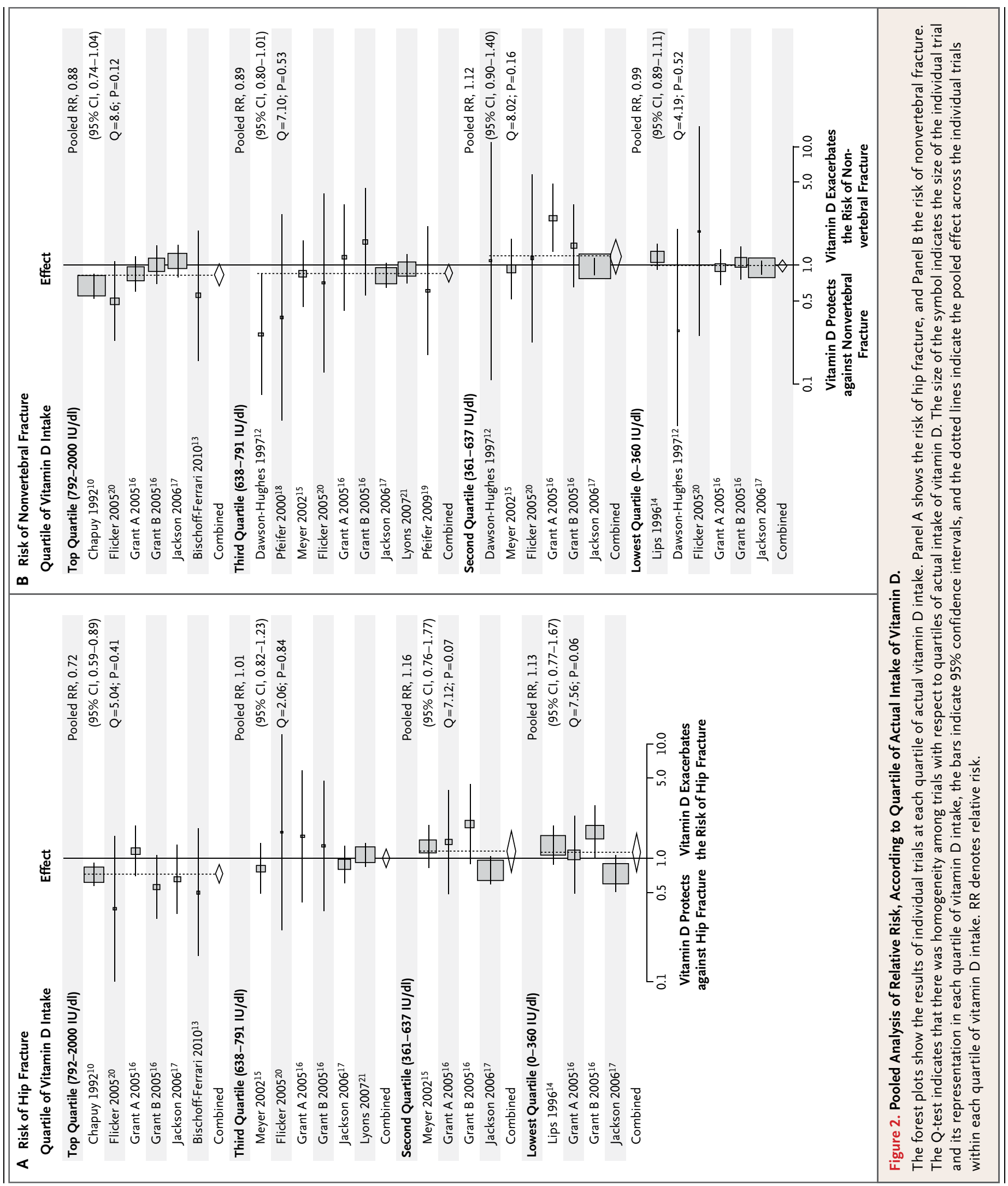




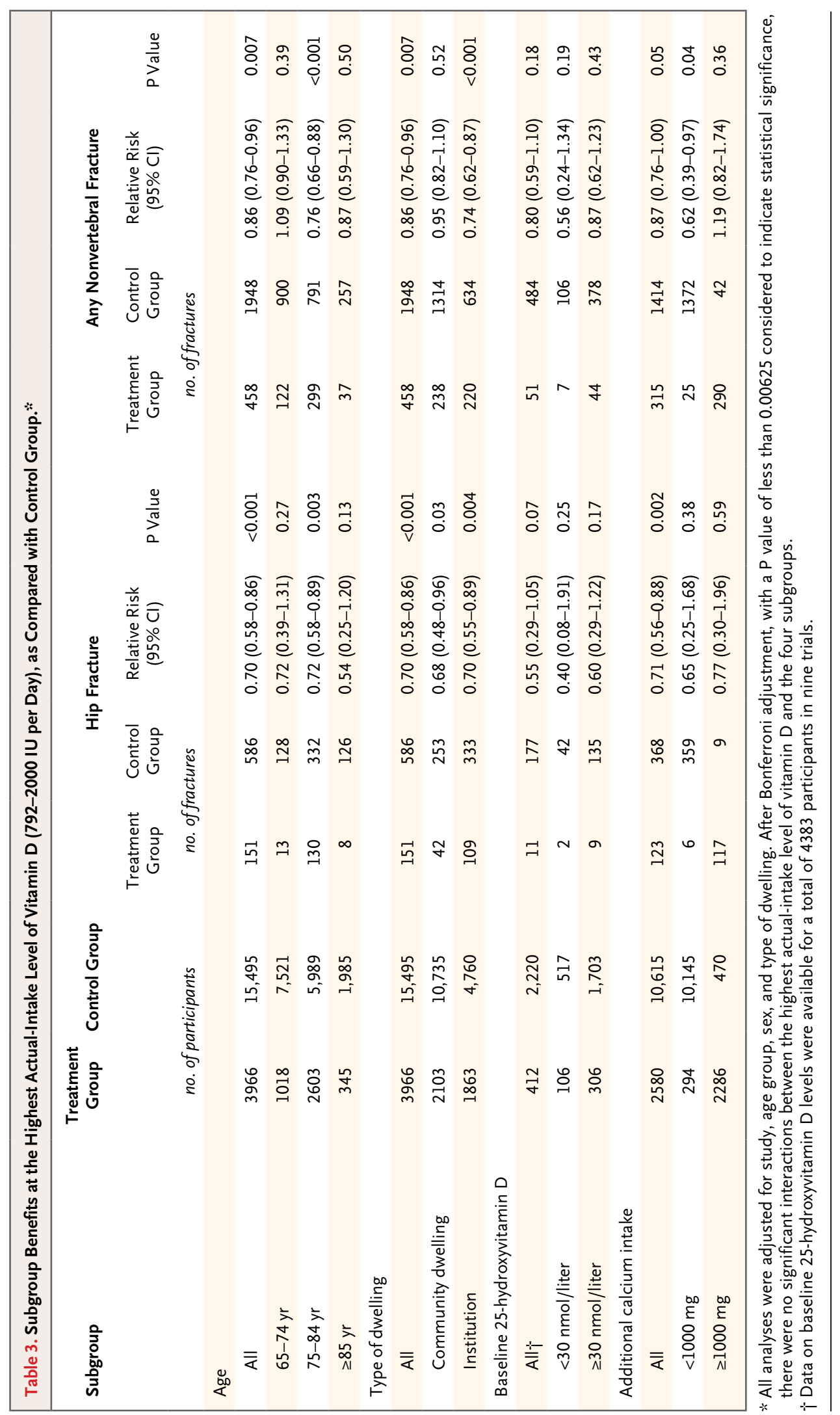

The New England Journal of Medicine 
which compared the highest actual-intake level with the lowest, regardless of study assignment (treatment or control). A dose-response relationship between vitamin $\mathrm{D}$ and fracture risk is further supported by our analysis of baseline levels of 25-hydroxyvitamin D and prospective fracture risk.

Our findings suggest that some previous highquality trials of vitamin D supplementation either showed no benefit owing to lower-than-intended doses of vitamin D or showed an unexpected benefit owing to higher-than-intended doses. For example, the RECORD trial by Grant et al. ${ }^{16}$ was designed with an intended dose of 800 IU per day, but the actual intake of vitamin $\mathrm{D}$ was lower, with a mean intake of 539 IU per day in the group that received vitamin $\mathrm{D}$ combined with calcium and 613 IU per day in the group that received vitamin D alone. Conversely, the Women's Health Initiative trial by Jackson et al. ${ }^{17}$ was designed with an intended dose of 400 IU per day, but the actual intake of vitamin $\mathrm{D}$ and the proportion of participants in the highest intake range were higher, which may in part explain the reduced risk of fracture that was observed in the older participants in that trial.

Previous meta-analyses have suggested that the benefits of vitamin $\mathrm{D}$ may be limited to older persons who live in institutions. ${ }^{4,6}$ Our subgroup analyses suggest that at the highest actual-intake level, the risk of hip fracture is reduced among all persons 65 years of age or older, whether they live in the community or in an institution. Our data further suggest that persons who are most vulnerable to vitamin $\mathrm{D}$ deficiency - those 85 years of age or older and those with very low baseline levels of 25-hydroxyvitamin D - benefit from vitamin D supplementation at least as much as others do. However, because of the reduced sample size and power, we are not able to determine whether this benefit is greater or simply equivalent.

Several previous meta-analyses suggested that the dose of vitamin $\mathrm{D}$ is irrelevant when vitamin D is combined with calcium. ${ }^{4-7}$ In contrast, our pooled subgroup analyses of the eight doubleblind, randomized, controlled trials that used vitamin D combined with calcium indicate that with combined supplementation, the risk of fracture is reduced only at the highest actual-intake level of vitamin D. Furthermore, our data suggest that at the highest actual-intake level of vitamin D, a smaller amount of calcium supplementation ( $<1000 \mathrm{mg}$ per day), as compared with a larger amount ( $\geq 1000 \mathrm{mg}$ per day), may be more beneficial in reducing the risk of fracture - a finding that is consonant with epidemiologic studies. ${ }^{23,24}$

Our sensitivity analysis suggests that the vitamin D dosing interval may be relevant for reducing the risk of fracture. When we included in our sensitivity analysis the trial by Sanders et al.,11 in which one annual dose of vitamin was administered, the risk reduction was attenuated. Similarly, another study of annual supplementation with injectable vitamin $\mathrm{D}$ showed a null effect on the risk of fracture. ${ }^{25}$ In contrast, a trial from which the source data set could not be retrieved showed that a dose of 100,000 IU of vitamin D taken orally every 4 months was associated with a $33 \%$ reduction in the risk of a first hip, wrist, or forearm fracture, suggesting that the 4-month dosing interval is satisfactory. ${ }^{8}$ More frequent dosing (daily or weekly) in adequate amounts is supported by our analysis as a means of lowering the risk of both hip and nonvertebral fractures.

The strengths of our pooled analysis are the large sample, the assessment of fracture risk by actual intake of vitamin D, and the consistency of the primary findings and the internal validation study. The principal limitation of our analysis is the unavailability of source data for 2 of the 14 qualifying trials ${ }^{8,9}$; however, inclusion of the trial-level data from these studies in a randomeffects meta-analysis did not alter our findings. A further limitation is that we could not assess the effect of the highest quartile of actual intake of vitamin D (792 to 1000 IU per day) without additional calcium, because all trials that gave higher doses of vitamin D ( $\geq 800$ IU per day with good adherence) also gave calcium. The threshold assessment of fracture was limited because baseline levels of 25-hydroxyvitamin D were available for only a subset of participants and because the assays used to measure 25-hydroxyvitamin varied among the studies. However, after adjustment for this variation and all other covariates, the doseresponse relationship remained significant.

Our findings support the most recent recommendation from the Institute of Medicine ${ }^{26}$ that persons 65 years of age or older receive 800 IU of vitamin $\mathrm{D}$ per day, but suggest that a 25 -hydroxyvitamin D level of more than $60 \mathrm{nmol}$ per liter may be most beneficial for reducing the risk of fractures. Furthermore, although our data did not allow us to determine whether the actual-intake level of a calcium supplement influenced the effect of vitamin $\mathrm{D}$ at the highest actual-intake 
level, it would be important for future studies to consider the possibility that a calcium-supplement intake of $1000 \mathrm{mg}$ per day or more, combined with high-dose vitamin D ( $\geq 800$ IU per day) may be harmful. Calcium supplements without vitamin D have been reported to increase the risk of hip fracture. ${ }^{27}$

In conclusion, our data suggest that high-dose vitamin D supplementation ( $\geq 800$ IU per day) may reduce the risk of hip fracture in persons 65 years of age or older, independently of type of dwelling, age, and sex. Furthermore, our data support a 25-hydroxyvitamin D level above $60 \mathrm{nmol}$ per liter for the prevention of fractures.

Supported by a professorship grant (PP00B-114864) from the Swiss National Foundations, a grant (DO-HEALTH-278588) from the European Commission Framework 7 Program, and DSM Nutritional Products.

Disclosure forms provided by the authors are available with the full text of this article at NEJM.org.

We thank Stephen M. Ferrari at the Center on Aging and Mobility, University of Zurich, for programming the pooled data set, and Dr. Geeske Peeters for help with the data translation and input of the Amsterdam Vitamin D Study.
REFERENCES

1. Melton LJ III, Crowson CS, O'Fallon WM. Fracture incidence in Olmsted County, Minnesota: comparison of urban with rural rates and changes in urban rates over time. Osteoporos Int 1999;9:29-37.

2. Gullberg B, Johnell O, Kanis JA. World-wide projections for hip fracture. Osteoporos Int 1997;7:407-13.

3. Bischoff-Ferrari HA, Willett WC, Wong $\mathrm{JB}$, et al. Prevention of nonvertebral fractures with oral vitamin $\mathrm{D}$ and dose dependency: a meta-analysis of randomized controlled trials. Arch Intern Med 2009; 169:551-61.

4. Cranney A, Horsley T, O'Donnell S, et al. Effectiveness and safety of vitamin D in relation to bone health. Evid Rep Technol Assess (Full Rep) 2007;August:1-235.

5. Boonen S, Lips P, Bouillon R, BischoffFerrari HA, Vanderschueren D, Haentjens P. Need for additional calcium to reduce the risk of hip fracture with vitamin D supplementation: evidence from a comparative metaanalysis of randomized controlled trials. J Clin Endocrinol Metab 2007;92:1415-23.

6. Avenell A, Gillespie WJ, Gillespie LD, O'Connell D. Vitamin D and vitamin D analogues for preventing fractures associated with involutional and post-menopausal osteoporosis. Cochrane Database Syst Rev 2009;2:CD000227.

7. DIPART (Vitamin D Individual Patient Analysis of Randomized Trials) Group. Patient level pooled analysis of $68500 \mathrm{pa}$ tients from seven major vitamin $D$ fracture trials in US and Europe. BMJ 2010; 340:b5463.

8. Trivedi DP, Doll R, Khaw KT. Effect of four monthly oral vitamin D3 (cholecalciferol) supplementation on fractures and mortality in men and women living in the community: randomised double blind controlled trial. BMJ 2003;326:469.

9. Chapuy MC, Pamphile R, Paris E, et al. Combined calcium and vitamin D3 supplementation in elderly women: confirmation of reversal of secondary hyperparathyroidism and hip fracture risk: the Decalyos II study. Osteoporos Int 2002; 13:257-64.

10. Chapuy MC, Arlot ME, Duboeuf F, et al. Vitamin $\mathrm{D}_{3}$ and calcium to prevent hip fractures in elderly women. $\mathrm{N}$ Engl J Med 1992;327:1637-42.

11. Sanders KM, Stuart AL, Williamson EJ, et al. Annual high-dose oral vitamin D and falls and fractures in older women: a randomized controlled trial. JAMA 2010; 303:1815-22. [Erratum, JAMA 2010;303: 2357.]

12. Dawson-Hughes B, Harris SS, Krall EA, Dallal GE. Effect of calcium and vitamin D supplementation on bone density in men and women 65 years of age or older. N Engl J Med 1997;337:670-6.

13. Bischoff-Ferrari HA, Dawson-Hughes B, Platz A, et al. Effect of high-dosage cholecalciferol and extended physiotherapy on complications after hip fracture: a randomized controlled trial. Arch Intern Med 2010;170:813-20.

14. Lips P, Graafmans WC, Ooms ME, Bezemer PD, Bouter LM. Vitamin D supplementation and fracture incidence in elderly persons: a randomized, placebocontrolled clinical trial. Ann Intern Med 1996;124:400-6.

15. Meyer HE, Smedshaug GB, Kvaavik E, Falch JA, Tverdal A, Pedersen JI. Can vitamin D supplementation reduce the risk of fracture in the elderly? A randomized controlled trial. J Bone Miner Res 2002;17:70915.

16. Grant AM, Avenell A, Campbell MK, et al. Oral vitamin D3 and calcium for secondary prevention of low-trauma fractures in elderly people (Randomised Evaluation of Calcium Or vitamin D, RECORD): a randomised placebo-controlled trial. Lancet 2005;365:1621-8.

17. Jackson RD, LaCroix AZ, Gass $M$, et al. Calcium plus vitamin D supplementation and the risk of fractures. N Engl J Med 2006;354:669-83. [Erratum, N Engl J Med 2006;354:1102.]

18. Pfeifer M, Begerow B, Minne HW, Abrams C, Nachtigall D, Hansen C. Effects of a short-term vitamin $\mathrm{D}$ and calcium supplementation on body sway and secondary hyperparathyroidism in elderly women. J Bone Miner Res 2000;15:1113-8. [Errata, J Bone Miner Res 2001;16:1735, 1935.]
19. Pfeifer $M$, Begerow B, Minne HW, Suppan K, Fahrleitner-Pammer A, Dobnig $H$. Effects of a long-term vitamin D and calcium supplementation on falls and parameters of muscle function in community-dwelling older individuals. Osteoporos Int 2009;20:315-22.

20. Flicker L, MacInnis RJ, Stein MS, et al. Should older people in residential care receive vitamin D to prevent falls? Results of a randomized trial. J Am Geriatr Soc 2005;53:1881-8.

21. Lyons RA, Johansen A, Brophy S, et al. Preventing fractures among older people living in institutional care: a pragmatic randomised double blind placebo controlled trial of vitamin D supplementation. Osteoporos Int 2007;18:811-8.

22. Liang K-Y, Self SG, Bandeen-Roche KJ, Zeger SL. Some recent developments for regression analysis of multivariate failure time data. Lifetime Data Anal 1995;1:40315.

23. Steingrimsdottir L, Gunnarsson O, Indridason OS, Franzson L, Sigurdsson G. Relationship between serum parathyroid hormone levels, vitamin D sufficiency, and calcium intake. JAMA 2005;294:2336-41. 24. Bischoff-Ferrari HA, Kiel DP, Dawson-Hughes B, et al. Dietary calcium and serum 25-hydroxyvitamin D status in relation to BMD among U.S. adults. J Bone Miner Res 2009;24:935-42.

25. Smith H, Anderson F, Raphael H, Maslin P, Crozier S, Cooper C. Effect of annual intramuscular vitamin $\mathrm{D}$ on fracture risk in elderly men and women - a population-based, randomized, doubleblind, placebo-controlled trial. Rheumatology (Oxford) 2007;46:1852-7.

26. Ross AC, Manson JE, Abrams SA, et al. The 2011 Dietary Reference Intakes for Calcium and Vitamin D: what dietetics practitioners need to know. J Am Diet Assoc 2011;111:524-7.

27. Bischoff-Ferrari HA, Dawson-Hughes $\mathrm{B}$, Baron JA, et al. Calcium intake and hip fracture risk in men and women: a metaanalysis of prospective cohort studies and randomized controlled trials. Am J Clin Nutr 2007;86:1780-90.

Copyright (c) 2012 Massachusetts Medical Society. 


\section{Supplementary Appendix}

This appendix has been provided by the authors to give readers additional information about their work.

Supplement to: Bischoff-Ferrari HA, Willett WC, Oray EJ, et al. A pooled analysis of vitamin D dose requirements for fracture prevention. N Engl J Med 2012;367:40-9. DOI: 10.1056/NEJMoa1109617. 
Appendix: 11-09617

June $11^{\text {th }} 2012-06-11$

A Pooled Analysis to Define Vitamin D Dose Requirements for Fracture Prevention

\section{Table of Contents Appendix:}

Appendix 1: Treatment dose, adherence-adjusted dose, and actual intake of vitamin $D$ and calcium in treated subjects and controls by trial

Page 2-3

Appendix 2: Influence of individual trials on fracture reduction at the highest actual vitamin D intake level

Page 4-7

Appendix 3: Influence of Sanders trial at the intent-to-treat level and the highest actual vitamin D intake quartile

Page 8

Appendix 4: Further sensitivity analyses

Page 9 
Appendix 1: Treatment dose, adherence-adjusted dose, and actual intake of vitamin D and calcium in treated subjects and controls by trial

\begin{tabular}{|c|c|c|c|c|c|c|}
\hline \multirow[b]{3}{*}{$\begin{array}{l}\text { Study } \\
\text { (n treatment group) }\end{array}$} & \multicolumn{3}{|c|}{ Vitamin D } & \multicolumn{3}{|c|}{ Calcium } \\
\hline & \multirow[b]{2}{*}{$\begin{array}{c}\text { Treated } \\
\text { dose }\end{array}$} & \multicolumn{2}{|c|}{ Mean } & \multirow[b]{2}{*}{$\begin{array}{c}\text { Treated } \\
\text { dose }\end{array}$} & \multicolumn{2}{|c|}{ Mean } \\
\hline & & $\begin{array}{l}\text { Adherence- } \\
\text { adjusted } \\
\text { treatment } \\
\text { dose }\end{array}$ & Actual dose & & $\begin{array}{l}\text { Adherence- } \\
\text { adjusted } \\
\text { treatment } \\
\text { dose }\end{array}$ & Actual dose \\
\hline $\begin{array}{l}\text { Chapuy } \mathbf{1 9 9 2}^{\mathbf{1 0}} \\
\text { Treatment }(\mathrm{n}=1634) \\
\text { Controls }(\mathrm{n}=1636)\end{array}$ & $\begin{array}{c}800 \\
0\end{array}$ & $\begin{array}{c}800 \\
0\end{array}$ & $\begin{array}{c}800 \\
0\end{array}$ & $\begin{array}{c}1200 \\
0\end{array}$ & $\begin{array}{c}1200 \\
0\end{array}$ & $\begin{array}{c}1200 \\
0\end{array}$ \\
\hline $\begin{array}{l}\text { Lips 1996 }^{\mathbf{1 4}} \\
\text { Treatment }(n=1291) \\
\text { Controls }(n=1287)\end{array}$ & $\begin{array}{c}400 \\
0\end{array}$ & $\begin{array}{c}340 \\
0\end{array}$ & $\begin{array}{c}340 \\
0\end{array}$ & $\begin{array}{l}0 \\
0\end{array}$ & $\begin{array}{l}0 \\
0 \\
\end{array}$ & $\begin{array}{l}0 \\
0 \\
\end{array}$ \\
\hline $\begin{array}{l}\text { Dawson-Hughes } \\
\mathbf{1 9 9 7}^{\mathbf{1 2}} \\
\text { Treatment }(\mathrm{n}=187) \\
\text { Controls }(\mathrm{n}=202) \\
\end{array}$ & $\begin{array}{c}700 \\
0 \\
\end{array}$ & $\begin{array}{c}618 \\
0 \\
\end{array}$ & $\begin{array}{c}618 \\
0 \\
\end{array}$ & $\begin{array}{c}500 \\
0 \\
\end{array}$ & $\begin{array}{c}441 \\
0 \\
\end{array}$ & $\begin{array}{c}441 \\
0 \\
\end{array}$ \\
\hline $\begin{array}{l}\text { Pfeifer 2000 }^{\mathbf{1 8}} \\
\text { Treatment }(\mathrm{n}=74) \\
\text { Controls }(\mathrm{n}=74)\end{array}$ & $\begin{array}{c}800 \\
0\end{array}$ & $\begin{array}{c}760 \\
0\end{array}$ & $\begin{array}{c}760 \\
0\end{array}$ & $\begin{array}{l}1200 \\
1200\end{array}$ & $\begin{array}{l}1140 \\
1140\end{array}$ & $\begin{array}{l}1140 \\
1140\end{array}$ \\
\hline $\begin{array}{l}\text { Meyer 2002 } \\
\text { Treatment }(\mathrm{n}=560) \\
\text { Controls }(\mathrm{n}=565)\end{array}$ & $\begin{array}{c}400 \\
0\end{array}$ & $\begin{array}{c}380 \\
0\end{array}$ & $\begin{array}{l}528 \\
159\end{array}$ & $\begin{array}{l}0 \\
0\end{array}$ & $\begin{array}{l}0 \\
0\end{array}$ & $\begin{array}{l}0 \\
0\end{array}$ \\
\hline $\begin{array}{l}\text { Flicker } \mathbf{2 0 0 5}^{\mathbf{2 0}} \\
\text { Treatment }(\mathrm{n}=304) \\
\text { Controls }(\mathrm{n}=297)\end{array}$ & $\begin{array}{c}1067 \\
0\end{array}$ & $\begin{array}{c}844 \\
0\end{array}$ & $\begin{array}{c}844 \\
0\end{array}$ & $\begin{array}{l}600 \\
600\end{array}$ & $\begin{array}{l}476 \\
466\end{array}$ & $\begin{array}{l}476 \\
466\end{array}$ \\
\hline $\begin{array}{l}\text { Grant } \mathbf{A}^{\mathbf{1 6}} \\
\text { Treatment }(n=1335) \\
\text { Controls }(n=1321)\end{array}$ & $\begin{array}{c}800 \\
0\end{array}$ & $\begin{array}{c}608 \\
0\end{array}$ & $\begin{array}{c}613 \\
6\end{array}$ & $\begin{array}{l}0 \\
0\end{array}$ & $\begin{array}{l}0 \\
0\end{array}$ & $\begin{array}{l}2 \\
3\end{array}$ \\
\hline $\begin{array}{l}\text { Grant B }^{16} \\
\text { Treatment }(n=1294) \\
\text { Controls }(n=1294)\end{array}$ & $\begin{array}{c}800 \\
0 \\
\end{array}$ & $\begin{array}{c}535 \\
0 \\
\end{array}$ & $\begin{array}{c}539 \\
6\end{array}$ & $\begin{array}{l}1000 \\
1000 \\
\end{array}$ & $\begin{array}{l}668 \\
680 \\
\end{array}$ & $\begin{array}{l}669 \\
683 \\
\end{array}$ \\
\hline $\begin{array}{l}\text { Jackson 2005 } \\
\text { Treatment }(n=6925) \\
\text { Controls }(n=6905)\end{array}$ & $\begin{array}{c}400 \\
0\end{array}$ & $\begin{array}{c}330 \\
0\end{array}$ & $\begin{array}{l}528 \\
199\end{array}$ & $\begin{array}{c}1000 \\
0\end{array}$ & $\begin{array}{c}825 \\
0\end{array}$ & $\begin{array}{c}1106 \\
290 \\
\end{array}$ \\
\hline $\begin{array}{l}\text { Lyons 2007 } \\
\text { Treatment }(\mathrm{n}=1715) \\
\text { Controls }(\mathrm{n}=1707)\end{array}$ & $\begin{array}{c}821 \\
0\end{array}$ & $\begin{array}{c}657 \\
0\end{array}$ & $\begin{array}{c}657 \\
0\end{array}$ & $\begin{array}{l}0 \\
0\end{array}$ & $\begin{array}{l}0 \\
0\end{array}$ & $\begin{array}{l}0 \\
0\end{array}$ \\
\hline $\begin{array}{l}\text { Pfeifer 2009 } \\
\text { Treatment }(\mathrm{n}=122) \\
\text { Controls }(\mathrm{n}=120)\end{array}$ & $\begin{array}{c}800 \\
0\end{array}$ & $\begin{array}{c}720 \\
0\end{array}$ & $\begin{array}{c}720 \\
0\end{array}$ & $\begin{array}{l}1000 \\
1000\end{array}$ & $\begin{array}{l}900 \\
900\end{array}$ & $\begin{array}{l}900 \\
900\end{array}$ \\
\hline $\begin{array}{l}\text { Bischoff-Ferrari } \\
\mathbf{2 0 1 0}^{\mathbf{1 3}} \\
\text { Treatment }(\mathrm{n}=86) \\
\text { Controls }(\mathrm{n}=87)\end{array}$ & $\begin{array}{c}2000 \\
800\end{array}$ & $\begin{array}{c}1949 \\
728\end{array}$ & $\begin{array}{c}1949 \\
728\end{array}$ & $\begin{array}{l}1000 \\
1000\end{array}$ & $\begin{array}{l}975 \\
909\end{array}$ & $\begin{array}{l}975 \\
909\end{array}$ \\
\hline
\end{tabular}


Legend Appendix 1: The difference between treatment dose and actual vitamin D intake (accounting for adherence and supplement use outside the study protocol) was most pronounced for the Grant A and Grant B trials. For the Jackson trial (WHI trial) ${ }^{17}$, the inclusion of the supplement dose outside the study protocol almost doubled the actual intake of vitamin D. The data set as published originally by Chapuy et al. included only adherent individuals. Two trials (Flicker and Lyons) tested vitamin D2, all other trials tested vitamin D3. 
Appendix 2: Influence of individual trials on fracture reduction at the highest actual vitamin D intake level

A) Hip fracture reduction at the highest actual intake level of vitamin D per day (range 7922000 IU/day)

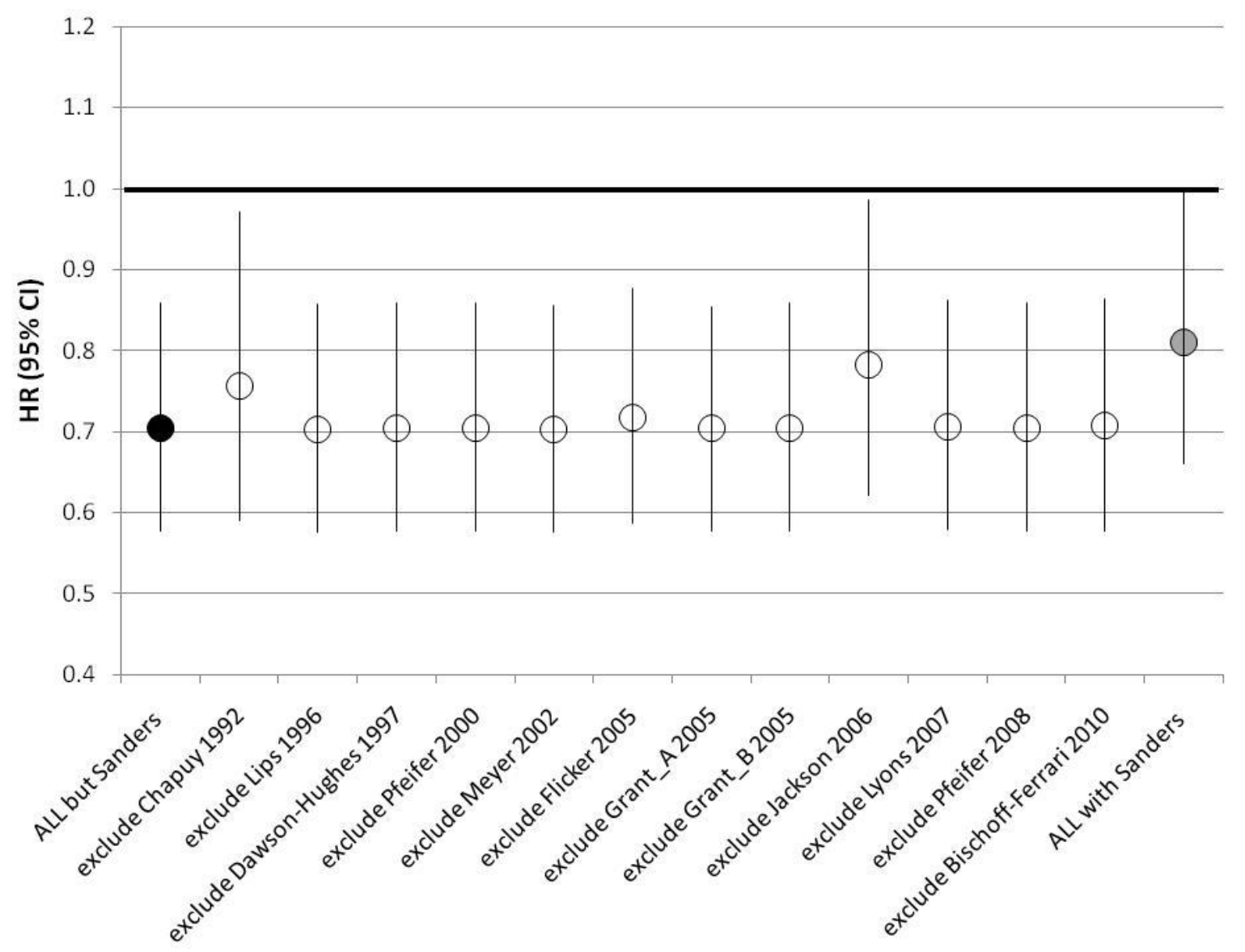


Legend Figure Appendix 2 A: The black dot shows the pooled effect of the highest actual intake level of vitamin D (range: 792-2000 IU per day) compared to placebo in all trials of the primary analysis with a $30 \%$ reduction of hip fractures $(\mathrm{HR}=0.70 ; 95 \% \mathrm{CI} 0.58-0.86)$. The unfilled dots indicate the same effect if an individual trial is excluded. The effect of vitamin D at the highest actual intake level is significant if any individual trial is excluded from the primary analysis. All analyses control for age group (65-74,75-85,85+), sex, institutionalized (yes/no) and study. If in a sensitivity analysis the Sanders trial ${ }^{11}$ with a large yearly dose of vitamin D is added to the primary analysis (grey filled dot), the benefit at the highest actual intake level of vitamin $\mathrm{D}$ is somewhat attenuated $(\mathrm{HR}=0.81 ; 95 \% \mathrm{CI} 0.66-1.00)$. 
B) Any non-vertebral fracture at the highest actual intake level of vitamin D (range 7922000IU/day)

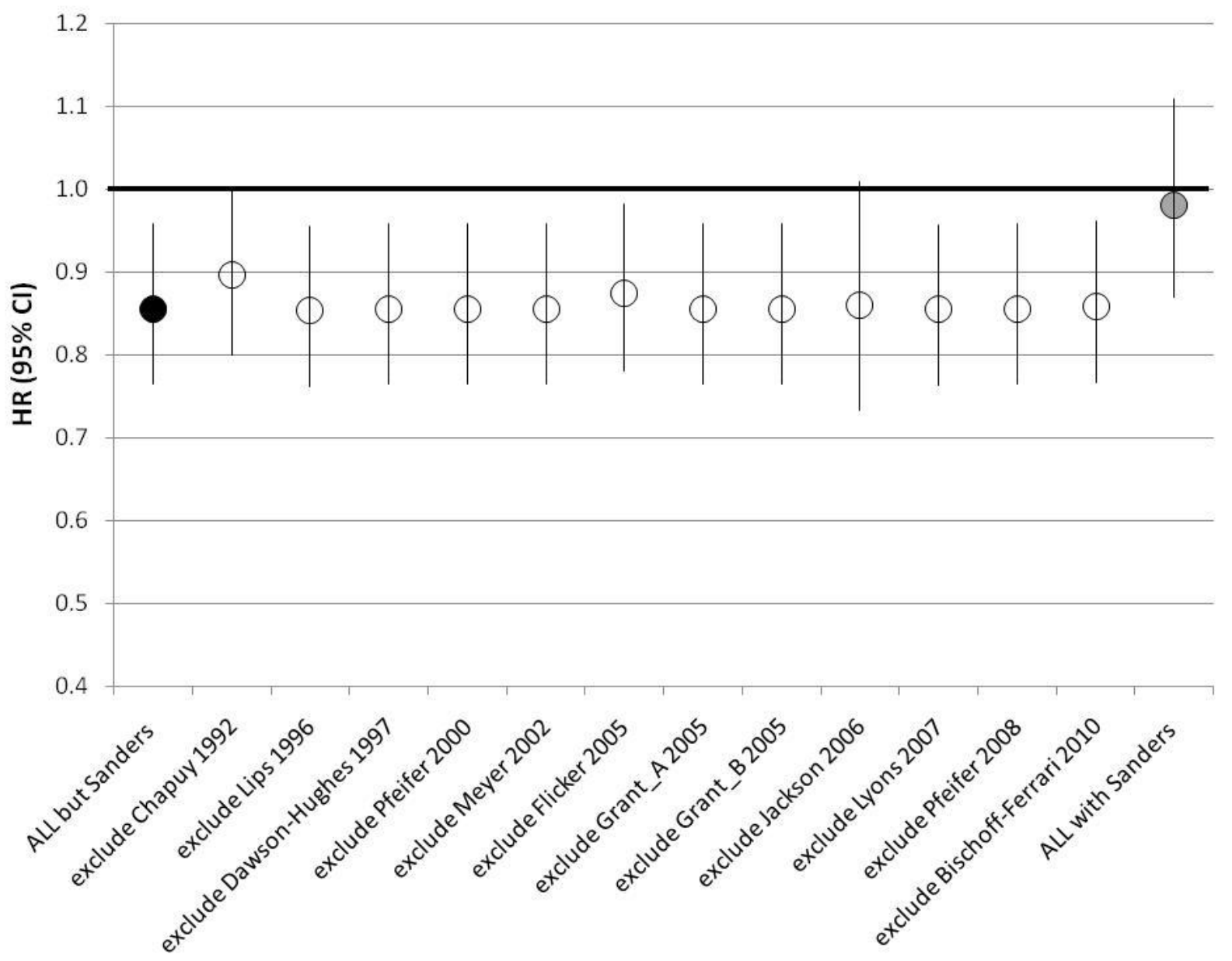


Legend Appendix 2 B: The black dot shows the pooled effect of the highest actual intake level of vitamin D (range: 792-2000 IU per day) compared to placebo in all trials of the primary analysis with a $14 \%$ reduction of non-vertebral fractures $(\mathrm{HR}=0.86 ; 95 \% \mathrm{CI} 0.76-0.96)$. The unfilled dots indicate the same effect if an individual trial is excluded. The effect of vitamin D at the highest actual intake level is significant if most individual trials are excluded, with some attenuation of the effect if the trials of Chapuy ${ }^{10}$ or Jackson (WHI) ${ }^{17}$ are excluded. All analyses control for age group $(65-74,75-85,85+)$, sex, institutionalized (yes/no) and study. If in a sensitivity analysis the Sanders trial ${ }^{11}$ with a large yearly dose of vitamin $\mathrm{D}$ is added to the primary analysis (grey filled dot), the benefit at the highest actual intake level of vitamin D is attenuated $(\mathrm{HR}=0.98 ; 95 \%$ CI 0.87-1.11). 
Appendix 3: Influence of Sanders Trials at the intent-to-treat level and the highest actual vitamin D intake quartile

If one additional trial that gave vitamin $\mathrm{D}$ at a very high annual dose (500,000 IU) was added to the primary pooled analyses ${ }^{11}$, fracture benefits were attenuated among the total group of 33,277 seniors age 65 and older. Comparing 16,657 seniors treated with vitamin D to 16,620 controls, vitamin D treatment reduced the risk of hip fracture non-significantly by $9 \%(\mathrm{HR}=0.91 ; 0.81$ $1.02)$ and the risk of any non-vertebral fracture non-significantly by $6 \%(\mathrm{HR}=0.94 ; 0.89-1.01)$. Based on our refined comparison by actual intake of vitamin D, treatment benefits were also attenuated at the highest intake level (792-2000 IU/day), both at the hip (HR $=0.81 ; 0.66-1.00)$ and at any non-vertebral fracture site ( $\mathrm{HR}=0.98 ; 0.87-1.11$; see Appendix 2 A and B). 
Appendix 4: Further sensitivity analyses

Findings at the highest intake level did not change appreciably if supplement use outside the study protocol was not adjusted for adherence (hip fracture: HR $=0.72 ; 0.59-0.87$; any nonvertebral fracture: $\mathrm{HR}=0.87 ; 0.78-0.97$ ), or if we added an estimated $100 \mathrm{IU}$ vitamin $\mathrm{D}$ as a supplement dose outside the study protocol to the treatment dose of participants from 2 trials where additional vitamin D intake was allowed but not documented (hip fracture: HR = 0.70; 0.57-0.86; any non-vertebral fracture: $\mathrm{HR}=0.85 ; 0.76-0.96$ ). 